\title{
PD-1 blockade in combination with zoledronic acid to enhance the antitumor efficacy in the breast cancer mouse model
}

\author{
Yuan $\mathrm{Li}^{1}$, Yang Du², Ting Sun ${ }^{1}$, Huadan Xue ${ }^{1}$, Zhengyu Jin ${ }^{1^{*}}$ and Jie Tian ${ }^{2 *}$
}

\begin{abstract}
Background: Blockade of PD-1 receptor may provide proof of concepts for the activity of an immune-modulation approach for the treatment of breast cancer (BC). Zoledronic acid (ZA) has been proven to inhibit angiogenesis, invasion, and adhesion of tumor cells. The aim of this study was to investigate the potential of monoclonal antibody against T cell checkpoint PD-1 in combination with chemotherapeutic drug ZA in BC mouse model.

Methods: The 4 T1-fLuc mouse BC model was used in this study. The anti-tumor efficacy of anti-PD-1 antibody alone or in combination with ZA was monitored by measuring bioluminescence imaging (BLI) and tumor volume. At the end of study, the flow cytometry was used to determine the immune cell population in tumors after different treatment.

Results: The results showed that mice treated with the combination therapy of anti-PD-1 antibody plus ZA exhibited better antitumor response compared to untreated controls or single therapy with no obvious toxicity.

Conclusion: Our study provides preclinical evidence for the enhanced BC treatment benefit through targeting cosignal molecules by combining anti-PD-1 antibody plus ZA treatment.
\end{abstract}

Keywords: PD-1, Zoledronic acid, Breast cancer, Therapy, Checkpoint inhibitior

\section{Background}

Breast cancer $(\mathrm{BC})$ is the highest incidence of female malignant neoplasia in developed countries and remains the leading causes of cancer death among women in less developed countries. Despite many undeniable therapeutic successes obtained, such as surgery, chemotherapy or radiation therapy, $\mathrm{BC}$ still remains one of the major threats to female health $[1,2]$. Therefore, it is urgent to find new and potential $\mathrm{BC}$ treatment strategies. Immunotherapy is an attractive and promising method for tumor management, which could identify and destroy tumor cells and prevent recurrence and metastatic by exploiting the ability of the immune system. Currently, the blockade of immune

\footnotetext{
*Correspondence: jin_zhengyu@163.com; jie.tian@ia.ac.cn
'Department of Radiology, Peking Union Medical College Hospital, Chinese

* Correspondence: jin_zhengyu@163.com; jie.tian@ia.ac.cn
'Department of Radiology, Peking Union Medical College Hospital, Chinese Academy of Medical Sciences \& Peking Union Medical College, No.1

Shuaifuyuan, Dongcheng District, Beijing 100730, China

${ }^{2}$ Key laboratory of Molecular Imaging of CAS, The State Key Laboratory of Management and Control for Complex Systems, Institute of Automation, Chinese Academy of Sciences, No. 95 ZhongGuanCun East Road, Beijing 100190, China
}

(c) The Author(s). 2018 Open Access This article is distributed under the terms of the Creative Commons Attribution 4.0 International License (http://creativecommons.org/licenses/by/4.0/), which permits unrestricted use, distribution, and reproduction in any medium, provided you give appropriate credit to the original author(s) and the source, provide a link to the Creative Commons license, and indicate if changes were made. The Creative Commons Public Domain Dedication waiver (http://creativecommons.org/publicdomain/zero/1.0/) applies to the data made available in this article, unless otherwise stated.

checkpoints is the most promising and attractive approach of immunotherapy in oncology [3].

Monoclonal antibodies (mAbs) directed against the programmed cell death protein-1 (PD-1) and against the cytotoxic T lymphocyte-associated antigen-4 (CTLA-4), are exhibiting promising cancer treatment effects, enhance antitumor immunity and improve patient survival, therefore have been approved for the therapies of nonsmall cell lung cancer and melanoma in clinics [4-6]. PD-1/PD-L1 results in negative regulation of T cells primarily within the tumor microenvironment. The blocking of PD-1 receptor may provide evidence for the activity of immune-modulation in the treatment of $\mathrm{BC}$ [7]. In addition, the inhibition of PD-1 signals has shown extremely promising signs of activity in $\mathrm{BC}$ [6]. Currently, two mAb treatments for the PD-1 (Pembrolizumab and Nivolumab) are being investigated for clinical use. Pembrolizumab has a significant application prospect in patients with recurrent and/or metastatic head and neck squamous cell carcinoma [8]. Due to its early 
success, more trials have been conducted to evaluate the efficacy of Nivolumab combined chemotherapy and/or radiation for definitive therapy in locoregionally advanced cancers are currently underway [9]. Allthough these results are encouraging, it remains to be determined in which therapeutic regimen blockade of PD-1 receptor will eventually to improve the prognosis of patients with the greatest impact: as a single agent, or combined with chemotherapy.

Zoledronic acid (ZA) is a third generation drug approved by FDA, typically used in the treatment and prevention of pathologic fractures and osteoporosis [10]. Additionally, it has found that ZA is an anti-resorptive drug that can directly target the tumor, improve immunosurveillance against tumor and to modulate macrophage differentiation microenvironment, target endothelial progenitor cells interfering with their differentiation, thus impair their supportive roles in cancer cells escaping from primary sites [11-13]. ZA has been used to treat many solid tumors, such as lung cancer, prostate cancer, colorectal cancer and recently in clinical trials as an adjuvant therapy for early $\mathrm{BC}[14,15]$. It was reported that ZA can prevent the tumor promoting effects of mesenchyme stem cells (MSCs) [16].

To further increase the immunotherapeutic efficacy, it was suggested that immunotherapy can be combined with new or standard therapies, with schedule and timing rationally designed. Based on the theories underlying the role of PD-1 and ZA as described above, antibodies blocking PD-1 and ZA are expected to comprise the next generation of therapy against human cancer. In this study, we tested the hypothesis that combined PD-1 antibody and ZA treatment for the treatment of BC.

\section{Methods}

\section{Materials}

Anti PD-1 mAb was obtained from BioXcell (West Lebanon, NH). ZA was got from Sigma Aldrich (St. Louis, MO, USA).

\section{Cell culture}

4 T1-fLuc cells (ATCC ${ }^{\oplus}$ CRL-2539TM) were got from the American Tissue Type Culture Collection (Manassas, VA, USA) and they were stably transfected with firefly luciferase reporter gene. 4 T1-fLuc cells were cultured in RPMI1640 medium (HyClone, Thermo Scientific, USA) contain $10 \%$ foetal calf serum (FCS; HyClone, Thermo Scientific) at $37{ }^{\circ} \mathrm{C}$ in a $5 \% \mathrm{CO}_{2}$ incubator. In a solid tumor model, mice were implanted subcutaneously (s.c.) in the right flank with $1 \times 10^{6}$ Cells in $100 \mu \mathrm{l}$ PBS.

\section{Establishment of the $\mathrm{BC}$ tumor bearing mouse model}

Five-six weeks old female Balb/c mice were obtained from the Department of Experimental Animals, Peking University Health Science Center (Bejing, China). All animal protocols were approved by the Institutional Animal Care and Use Committee in Peking University (Permit Number: 2011-0039), and all procedures were in accordance with approved guidelines. Mice were randomly divided into control and treatment groups.

\section{Anti-PD-1 mAb and ZA treatment}

One day before the injection of tumor cells, mice were treated with ZA in $100 \mu \mathrm{l}$ phosphate-buffered saline (PBS) intraperitoneally (i.p.) at a dose of $100 \mu \mathrm{g} / \mathrm{kg}$ every 2 days after the tumor inoculation (ZA group, $n=10$; Anti-PD-1 mAb plus ZA, $\mathrm{n}=10$ ). Anti-PD-1 antibody was injected i.p. at a dose of $200 \mu \mathrm{g} / \mathrm{kg}$ after the tumor cell injection (Anti-PD-1 mAb group, $\mathrm{n}=10$ ) every 2 days. Control group $(\mathrm{n}=10)$ was injected i.p. with equal volume of PBS.

\section{Mice body weight and tumor volume measurement after} different treatment

Electronic balance was used to measure mice body weight every 3 days. The tumor volume was estmated by measuring the largest (a) and smallest (b) diameters to calculate the tumor volume every 3 days, and the tumor volume calculated according to the following formula: Tumor Volume $\left(\mathrm{mm}^{3}\right)=\mathrm{a} \times \mathrm{b}^{2} / 2$.

\section{Bioluminescence imaging (BLI)}

For the in vivo drug treatment evaluation among 4 groups (10 mice each group), Xenogen IVIS Lumina II system (Perkin Elmer, Waltham, MA, USA) was used to monitor BLI as detailed previously [17] every 3 days during drug treatment. D-Luciferin was injected i.p. at a dose of $150 \mathrm{mg} / \mathrm{kg}$ and after $10 \mathrm{~min}$ mice were imaged dynamically during drug treatment. The imaging signal of regions of interest (ROI) was quantified by the mean photons per second per square centimeter per steradian $\left(\mathrm{p} / \mathrm{s} / \mathrm{cm}^{2} / \mathrm{sr}\right)$.

\section{Flow cytometry}

Tumor-infiltrating lymphocytes (TILs) were isolated from $4 \mathrm{~T} 1$ tumors after treatment. Cells were stained with the following antibodies: CD45-e450, CD3percy525, CD8-percy7, CD25-APCcy7, CD11b-APC (eBioscience, San Diego, CA). The flow cytometry was performed by using FACS Aria III (BD Biosciences, San Jose, CA, USA).

\section{Histology examination and immunofluorescence staining}

After the in vivo experiments, the tumors and also major organs including heart, liver, spleen, lung, and kidney were collected and fixed in the formalin. The paraffin sections were cut at 6-8 $\mu \mathrm{m}$ thickness and stained with hematoxylin and eosin. Microscope (Leica, Wetzlar, Germany) was used to take the images. In additon, 
tumors were excised, embedded in optimal cutting temperature (OCT) medium, subjected to immunofluorescence staining.

\section{Serum ELISA analysis of IL-18 and IFN- $\gamma$}

Levels of plasma interleukin (IL)-18 and interferon (IFN) $-\gamma$ of mouse origin were analyzed using the Quantikine ELISA kits (R\&D Systems). All analyses were in triplicate.

\section{Statistical analysis}

GraphPad Prism V5.0 (GraphPad Software, Inc., San Diego, CA) was used to perform statistical analyses. Results are expressed as the means and standard error of the mean (SEM). One- and two-way analyses of variances (ANOVA) and Tukey's multiple comparisons test or Student's $\mathrm{t}$-test were used for data analysis to determine statistical significance between treatment groups. $p$ values $<0.05$ were considered statistically significant.

\section{Results}

Combination therapy group showed the most effective antitumor effects monitored using BLI and the tumor volume In order to evaluate the different therapeutic efficacy BLI is used which is a sensitive indicator of tumor growth. In the control group, the BLI light intensity greatly increased during the 15-day observation (Fig. 1a (a)-(e)), whereas the BLI light intensities of ZA (Fig. 1a (f)-(j)), the anti-PD-1 mAb (Fig. 1a (k)-(o)) and the anti-PD-1 mAb plus ZA (Fig. 1 (p)-(t)) treatment groups increased slowly compared with the control group during 15 day-treatment. The BLI light intensity of tumors was further calculated and the results showed that anti-PD-1 mAb plus ZA treatment exhibited the lowest light intensity compared with other groups. Compared with the control group and the single treatment groups, the tumor growth inhibition effect was dramatic when the anti-PD-1 mAb were combined with ZA treatment.

The tumor volume was also measured dynamically for the assessment of the anti-tumor activity of anti-PD-1 $\mathrm{mAb}$ and ZA. The results were consistent with the in vivo BLI observation, showing that the most effective antitumor effects were the combination of anti-PD-1 mAb and ZA treatment (Fig. 1c). Compared with the anti-PD$1 \mathrm{mAb}$ or ZA blockade only, and combination therapy groups significantly inhibited the tumor growth.

\section{The body weight of the tumor-bearing mice not be affected after different treatment}

Moreover, the safety of treatment was also evaluated dynamically over a 15-day observation period. We found that the behavior and the body weight of the tumorbearing mice not be affected (Fig. 2). No noticeable

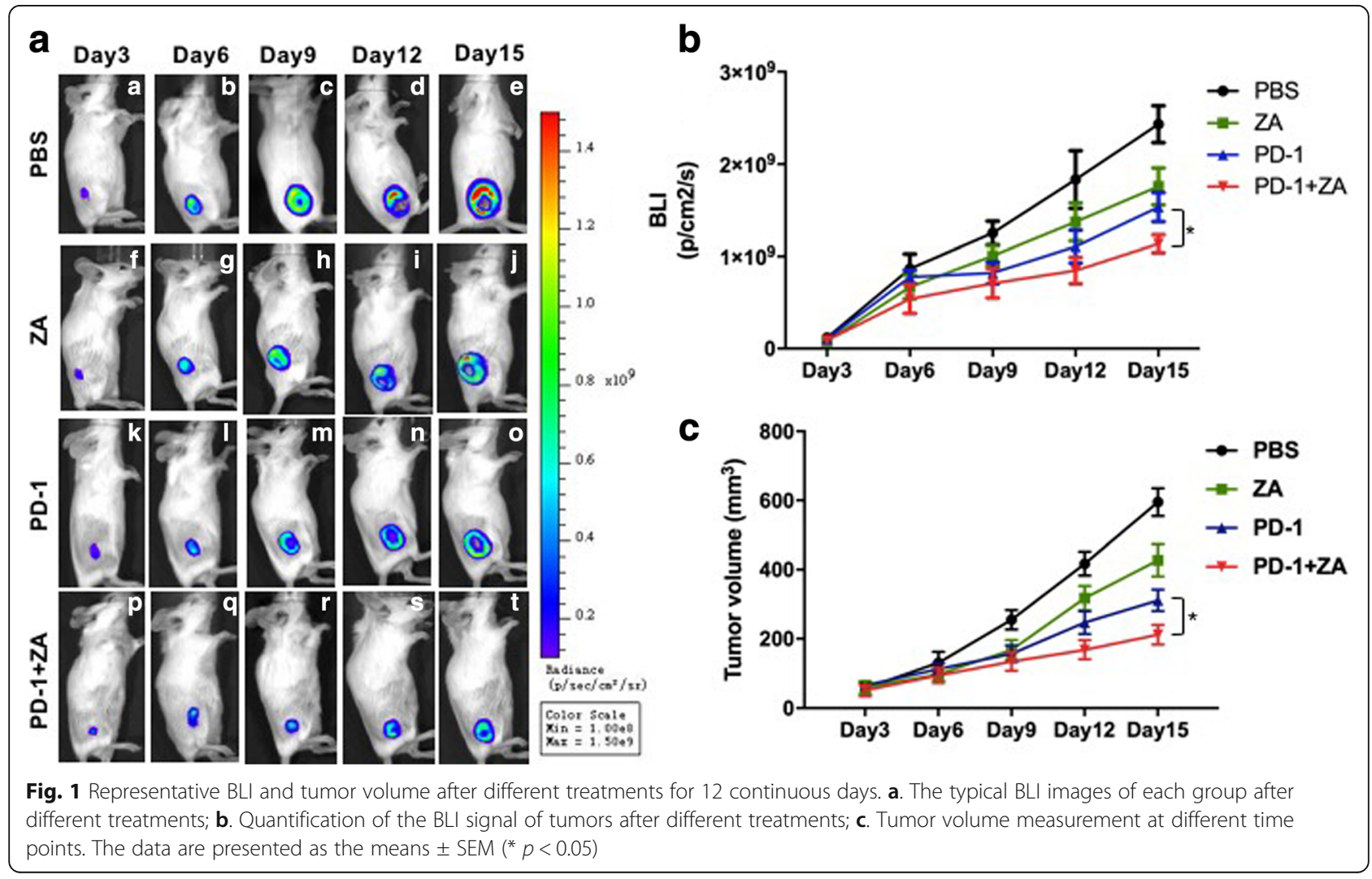




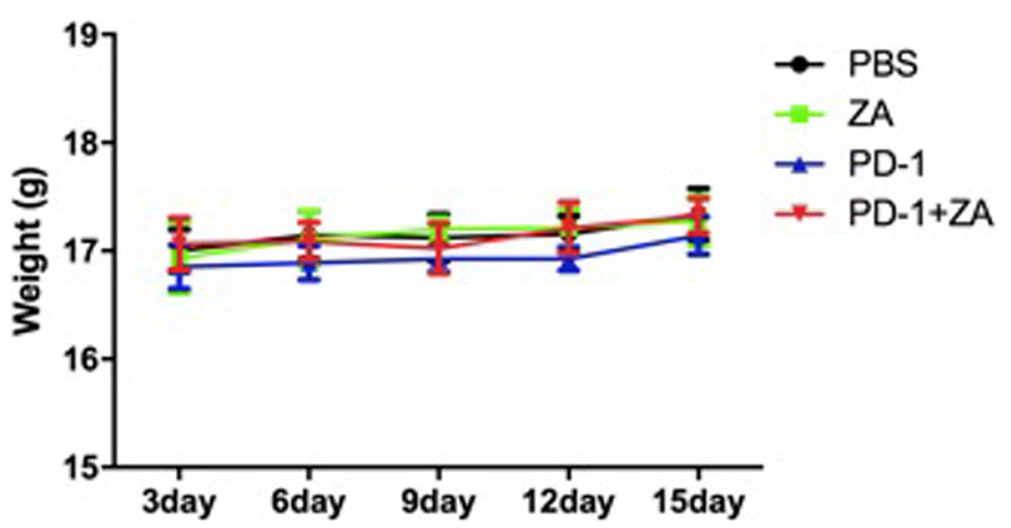

Fig. 2 The mouse body weight changes after treatment for 15 continuous days

tissue damages or any other toxic effects on the major organs (Fig. 3) was founded, which indicate that the dosing regimens were well tolerated with no serious side effects.

\section{Flow cytometry analysis and immunofluorescence} staining analysis of tumor infiltrating lymphocytes (TILs) and macrophages

Moreover, the effects of anti-PD-1 mAb and ZA on TILs using flow cytometry analysis and immunofluorescence staining (Fig. 4). There were relatively more $\mathrm{CD}^{+} \mathrm{T}$ cells in the $\mathrm{CD}^{+} \mathrm{T}$ cell population in the anti-PD-1
$\mathrm{mAb}$ plus ZA group compared to the anti-PD-1 mAb and ZA single treatment groups. There was no difference in terms of $\mathrm{CD}_{4}^{+} \mathrm{T}$ cell status in the $\mathrm{CD}^{+} \mathrm{T}$ cell population. ZA group had a significant decrease in the prevalence of myeloid derived suppressor cells (MDSCs) compared to controls ( $" p<0.05)$ (Fig. 4a). In addition, the immunofluorescence staining result show the increased $\mathrm{CD}^{+} \mathrm{T}$ cells and decreased MDSCs in treated mice which further confirm the flow cytometry findings (Fig. 4b), indicating the ability of anti-PD-1 mAb plus $\mathrm{ZA}$ to promote $\mathrm{CD} 8^{+}$cells infiltration into tumors.

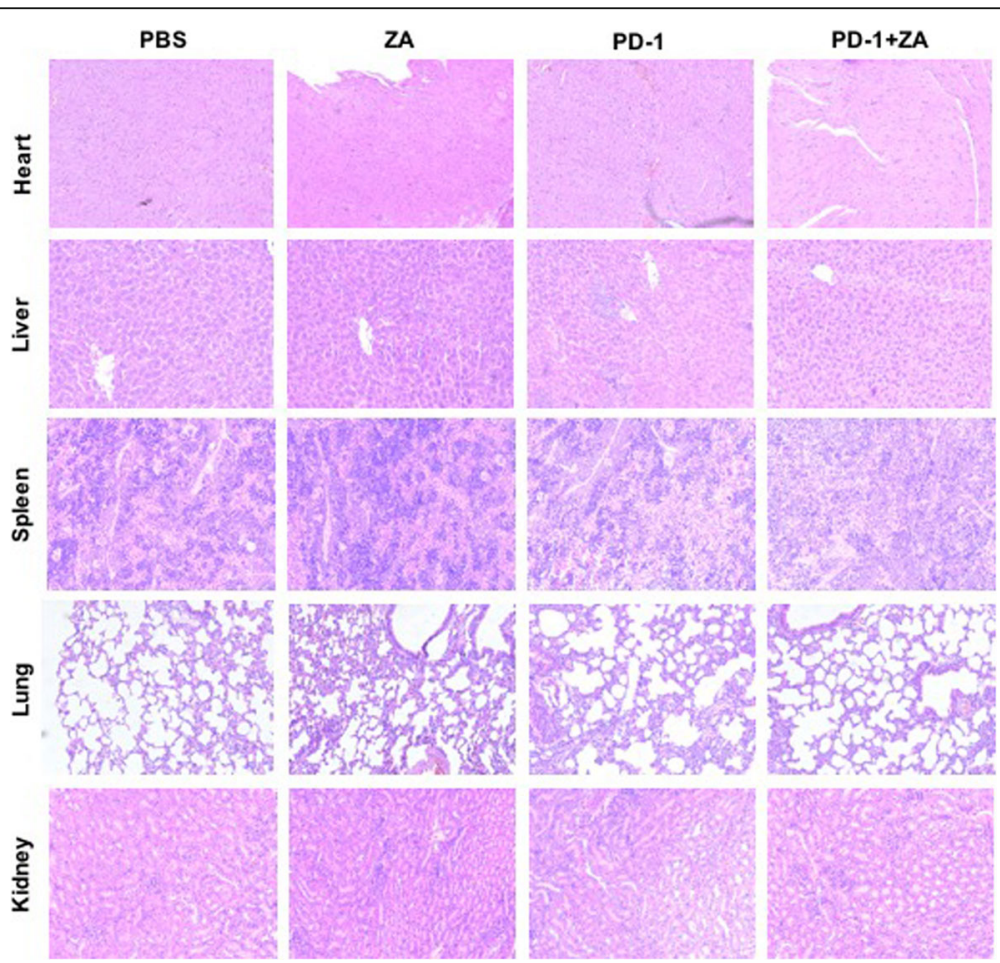

Fig. 3 Histological toxicity evaluation of major organs after treatment. H\&E staining of the heart, liver, spleen, lung, and kidney harvested from different groups of mice at 15 day after different treatment 

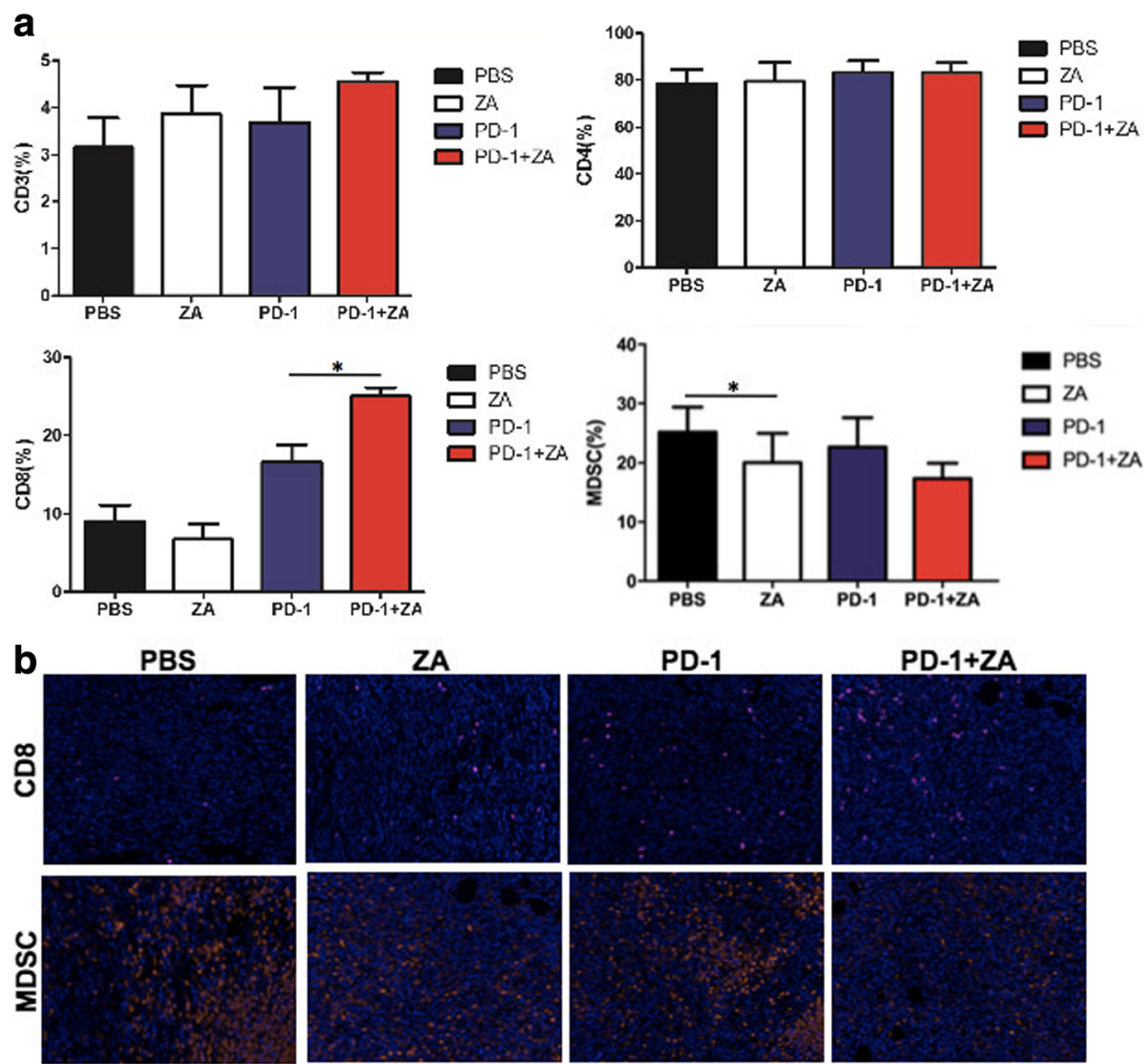

Fig. 4 The analysis of TILs in tumors after different treatments using flow cytometry and immunofluorescence staining. a Flow cytometry data for the $\mathrm{CD}^{+} \mathrm{T}$ cell population, $\mathrm{CD}^{+}$in the $\mathrm{CD}^{+} \mathrm{T}$ cell population, $\mathrm{CD}^{+}$in $\mathrm{CD}^{+} \mathrm{T}$ cells, and MDSC cells. ${ }^{*} P<0.05$. $\mathbf{b}$ Immunofluorescence staining of $\mathrm{CD}^{+}$and $\mathrm{CD} 11 \mathrm{~b}^{+}$MDSC cells in the tumor tissues from $4 \mathrm{~T} 1$ mice after different treatments

Increased IFN-r and IL 18 expression in the combination therapy group by serum ELISA analysis

Next, ELISA analysis was used to examine the expression levels of interferon (IFN)- $\gamma$ and Interleukin (IL-18) for a better understanding of how the immune system responds to anti-PD-1 mAb and ZA treatment (Fig. 5). There was approximately 1.7 -fold increase in IFN- $\gamma$ expression in the anti-PD-1 mAb plus ZA-treated mice compared to the control mice and there was significant increase in the anti-PD-1 mAb plus ZA-treated mice compared to the PD-1 treated mice. The result of IL-18 show that there was significant increase in anti-PD-1 $\mathrm{mAb}$ plus ZA-treated mice compared to the control treated mice, but there was no significant difference between anti-PD-1 mAb plus ZA-treated mice and the anti-PD-1 mAb treated mice.

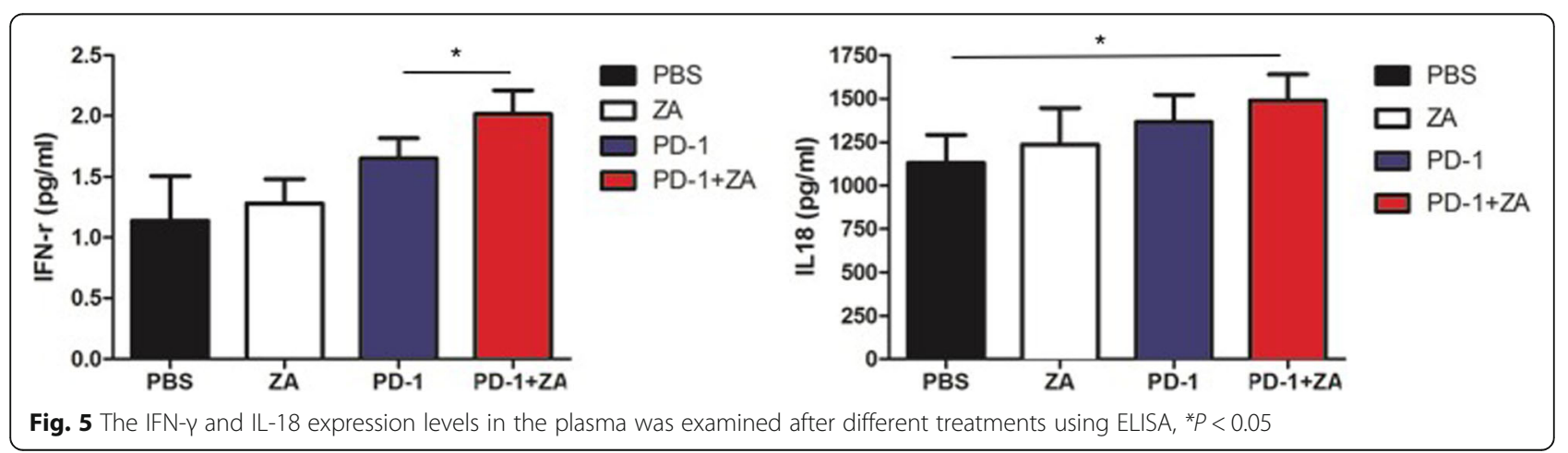




\section{Discussion}

Although immune checkpoint inhibitors alone have certain anti-tumor effect and immune modulation function, combination therapy can be more effective, including radiation therapy, biological agents and cell vaccine therapies. This is the first report on the use of anti-PD-1 mAb plus ZA for breast tumor therapy. In this study, we found that mice treated with the combination therapy of anti-PD-1 antibody plus ZA exhibited better antitumor response compared to untreated controls or single therapy as demonstrated by BLI imaging and tumor volume measurement with no obvious toxicity. The possible underlying mechanism was also delineated in this study.

The immune system plays a dual role in tumor immune surveillance and progression, and modulating the immune system is a promising treatment strategy for BC. Immune checkpoint blockade is a new approach for cancer immunotherapy and immune checkpoint blockade expressed on T-cell surface play an important role in this setting sending positive or negative signals to $\mathrm{T}$ cells. PD-1and PD-L1/2 axis are negative signals to inhibit $\mathrm{T}$-cell immune response. $\mathrm{PD}-1 / \mathrm{PD}-\mathrm{L} 1$ results in negative regulation of $\mathrm{T}$ cells primarily within the tumor microenvironment. PD-1, also called CD279, a 55-kDa type I trans-membrane glycoprotein and a member of the immunoglobulin superfamily, has been well characterized as a negative regulator of $\mathrm{T}$ cells and functions by delivering inhibitory signals. PD-1 over-expression has been implicated in diverse array of tumor types because of its participation in signaling pathways regulating attenuated $\mathrm{CD}^{+} \mathrm{T}$ cell function and enhanced Treg cell activity, which creates an inhibitory environment in the tumors. In a subgroup of thymic T-lymphocytes, PD-1 is produced in a way of constitutive expression, with up-regulated expression found in activated T-cells, B-cells, and myeloid cells [18-20]. These findings suggest that PD-1 is a promising biomarker of $\mathrm{BC}$ and a potential therapeutic target itself. On the other hand, anti-PD-1 mAb was reported to show an encouraging antitumor activity in combination with chemotherapy in advanced non-small cell lung cancer [21]. In this study, PD-1 blockade treatment showed significantly delayed tumor growth. IL-18 and IFN- $\gamma$ levels both play an important role in innate and adaptive immune responses. In the absence of Th1-like cytokines, IL-18 not only accelerates tumor progression but also promote PD-1 express on mature NK cells. As a cytokine, IFN- $\gamma$ i is critical for natural immunity and adaptive immunity. Once antigen-specific immunity develops, the activated effector T cells could secrete IFN- $\gamma$ [22]. Serum ELISA analyses of IL-18 and IFN- $\gamma$ data showed that they were increased in the PD-1 treated mice. These findings suggest that PD-1 is potential therapeutic target itself and indicative of a potential systemic host immune response.
It is found that ZA has direct anti-tumor efficacy, and is often treated as a combination of $\mathrm{BC}$. It was reported that ZA can inhibit the process of multiple intracellular, which was of great significance to cancer cell proliferation and the apoptosis of human leukemic cell lines [23]. In addition, ZA could be a potential anticancer agent by inhibiting angiogenesis, and affects $\mathrm{BC}$ metastasis to visceral organs as well as bone through inhibition of migration and invasion of BC cells [24]. Moreover, ZA has been shown to improve immunesurveillance against tumors, to inhibit spontaneous mammary cancerogenesis, opening new possibilities for its treatment application. ZA reduces cancer aggressiveness through abrogating the supportive role of tumor microenvironment. In this study, our flow cytometry data on TILs revealed that there were relatively more $\mathrm{CD}^{+}$cells, which mainly have an antitumor growth function. The anti-tumor mechanism of PD-1 may be related to the recovery of $\mathrm{CD}^{+}$cell number, thus relieving the immune suppression and enhancing anti-tumor function. This finding indicated that PD-1 mAb simultaneously works as an adjuvant immunotherapy for ZA chemotherapy. The data suggested that the combination therapy exhibited more efficient antitumor effects with minimal chemotoxicity for the treatment of $4 \mathrm{~T} 1 \mathrm{BC}$.

\section{Conclusions}

In conclusion, our study indicates that combination therapy with PD-1 blockade and ZA showed significantly inhibit tumor growth, highlighting its promising clinical translational ability for breast tumor management. Our results reveal a potential strategy for immunotherapy with ZA for breast cancer.

\section{Abbreviations}

BC: Breast cancer; BLI: Bioluminescence imaging; CTLA-4: Cytotoxic T lymphocyte-associated antigen-4; IFN- $\gamma$ : Interferon- $\gamma$; IL-18: Interleukin 18; mAbs: Monoclonal antibodies; MSCs: Mesenchyme stem cells; PBS: Phosphate-buffered saline; PD-1: Programmed cell death protein-1; ROI: Regions of interest; RPMI: Roswell Park Memorial Institute; ZA: Zoledronic acid

\footnotetext{
Acknowledgements

We would like to thank everyone at the Department of Radiology, Peking Union Medical College Hospital, and Key laboratory of Molecular Imaging of CAS, Institute of Automation, Chinese Academy of Sciences for invaluable help with this study.

\section{Funding}

This paper is supported by National Natural Science Foundation of China under Grant No. 81227901, 81470083, 81527805, 61231004, 81171390, Key Projects in the National Science \& Technology Pillar Program during the Twelfth Five-year Plan Period 2012BAI23B06, the Strategic Priority Research Program from Chinese Academy of Sciences under Grant No. XDB02060010, the International Innovation Team of CAS under Grant No. 20140491524, Beijing Municipal Science \& Technology Commission No. Z161100002616022. All funding bodies had no role in the study design, collection, analysis, interpretation of data, and writing manuscript.
} 


\section{Availability of data and materials}

The datasets used and/or analysed during the current study are available from the corresponding author on reasonable request.

\section{Authors' contributions}

$Y L$ and YD conceived and designed the experiments; YL performed the experiments; YL and YD analyzed the data and wrote the manuscript; TS and $\mathrm{HX}$ contributed materials and analysis tools and performed statistical analysis; ZJ and JT contributed to discussions, interpretation of the data and revision of the manuscript. All authors reviewed and approved the final manuscript.

\section{Ethics approval}

All animal experimental protocols were approved by the Institutional Animal Care and Use Committee at Peking University (Permit Number: 2011-0039), and all procedures were performed in accordance with the approved guidelines

\section{Competing interests}

The authors declare that they have no competing interest.

\section{Publisher's Note}

Springer Nature remains neutral with regard to jurisdictional claims in published maps and institutional affiliations.

Received: 19 October 2017 Accepted: 19 April 2018

Published online: 19 June 2018

\section{References}

1. Maccio A, Madeddu C, Mantovani G. Adipose tissue as target organ in the treatment of hormone-dependent breast cancer: new therapeutic perspectives [J]. Obes Rev. 2009;10(6):660-70.

2. Torre LA, Bray F, Siegel RL, et al. Global cancer statistics, 2012[J]. CA Cancer J Clin. 2015;65(2):87-108.

3. Su M, Huang CX, Dai AP. Immune checkpoint inhibitors: therapeutic tools for breast Cancer[]]. Asian Pac J Cancer Prev. 2016;17(3):905-10.

4. Brahmer JR, Tykodi SS, Chow LQ, et al. Safety and activity of anti-PD-L1 antibody in patients with advanced cancer[J]. N Engl J Med. 2012;366(26): 2455-65.

5. Hodi FS, O'Day SJ, Mcdermott DF, et al. Improved survival with ipilimumab in patients with metastatic melanoma[J]. N Engl J Med. 2010;363(8):711-23.

6. Bedognetti $\mathrm{D}$, Maccalli $\mathrm{C}$, Bader SB, et al. Checkpoint inhibitors and their application in breast Cancer[J]. Breast Care (Basel). 2016;11(2):108-15.

7. Migali C, Milano M, Trapani D, et al. Strategies to modulate the immune system in breast cancer: checkpoint inhibitors and beyond[]]. Ther Adv Med Oncol. 2016;8(5):360-74.

8. Nivolumab Doubles Survival for Patients with HNSCC[J]. Cancer Discov. 2016;6(7):F3

9. Mann JE, Hoesli R, Michmerhuizen NL, et al. Surveilling the potential for precision medicine-driven PD-1/PD-L1-targeted therapy in HNSCC[J]. J Cancer. 2017:8(3):332-44.

10. Melani C, Sangaletti S, Barazzetta FM, et al. Amino-biphosphonate-mediated MMP-9 inhibition breaks the tumor-bone marrow axis responsible for myeloid-derived suppressor cell expansion and macrophage infiltration in tumor stroma[J]. Cancer Res. 2007;67(23):11438-46.

11. Yamada J, Tsuno NH, Kitayama J, et al. Anti-angiogenic property of zoledronic acid by inhibition of endothelial progenitor cell differentiation[J]. J Surg Res. 2009;151(1):115-20.

12. Coscia M, Quaglino E, lezzi $M$, et al. Zoledronic acid repolarizes tumourassociated macrophages and inhibits mammary carcinogenesis by targeting the mevalonate pathway[J]. J Cell Mol Med. 2010;14(12):2803-15.

13. Comito $\mathrm{G}$, Segura $\mathrm{CP}$, Taddei $\mathrm{ML}$, et al. Zoledronic acid impairs stromal reactivity by inhibiting M2-macrophages polarization and prostate cancerassociated fibroblasts[]]. Oncotarget. 2016;

14. Barrett-Lee P, Casbard A, Abraham J, et al. Oral ibandronic acid versus intravenous zoledronic acid in treatment of bone metastases from breast cancer: a randomised, open label, non-inferiority phase 3 trial[J]. Lancet Oncol. 2014;15(1):114-22

15. Coleman R, Cameron D, Dodwell D, et al. Adjuvant zoledronic acid in patients with early breast cancer: final efficacy analysis of the AZURE (BIG 01/04) randomised open-label phase 3 trial[J]. Lancet Oncol. 2014:15(9):9971006.
16. Jia XH, Du Y, Mao D, et al. Zoledronic acid prevents the tumor-promoting effects of mesenchymal stem cells via MCP-1 dependent recruitment of macrophages[]]. Oncotarget. 2015;6(28):26018-28.

17. Wang L, Su W, Liu Z, et al. CD44 antibody-targeted liposomal nanoparticles for molecular imaging and therapy of hepatocellular carcinoma[J]. Biomaterials. 2012;33(20):5107-14

18. Latchman Y, Wood CR, Chernova T, et al. PD-L2 is a second ligand for PD-1 and inhibits T cell activation[J]. Nat Immunol. 2001;2(3):261-8.

19. Kitazawa Y, Fujino M, Wang Q, et al. Involvement of the programmed death-1/programmed death-1 ligand pathway in CD4+CD25+ regulatory T-cell activity to suppress alloimmune responses[]]. Transplantation. 2007; 83(6):774-82.

20. Ren HT, Li YM, Wang XJ, et al. PD-1 rs2227982 polymorphism is associated with the decreased risk of breast Cancer in northwest Chinese women: a hospital-based observational study[J]. Medicine (Baltimore). 2016;95(21): e3760.

21. Kanda S, Goto K, Shiraishi H, et al. Safety and efficacy of nivolumab and standard chemotherapy drug combination in patients with advanced nonsmall-cell lung cancer: a four arms phase lb study[]]. Ann Oncol. 2016;27(12): $2242-50$.

22. Iwai Y, Hemmi H, Mizenina O, Kuroda S, Suda K, Steinman RM. An IFNgamma-IL-18 signaling loop accelerates memory CD8+ T cell proliferation PLoS One. 2008;3(6):e2404.

23. Kuroda J, Kimura S, Segawa $\mathrm{H}$, et al. The third-generation bisphosphonate zoledronate synergistically augments the anti-Ph+ leukemia activity of imatinib mesylate[J]. Blood. 2003:102(6):2229-35.

24. Hiraga T, Williams PJ, Ueda A, et al. Zoledronic acid inhibits visceral metastases in the 4T1/luc mouse breast cancer model[J]. Clin Cancer Res. 2004;10(13):4559-67.

\section{Ready to submit your research? Choose BMC and benefit from:}

- fast, convenient online submission

- thorough peer review by experienced researchers in your field

- rapid publication on acceptance

- support for research data, including large and complex data types

- gold Open Access which fosters wider collaboration and increased citations

- maximum visibility for your research: over $100 \mathrm{M}$ website views per year

At BMC, research is always in progress.

Learn more biomedcentral.com/submissions 